\title{
Dissociation Constants of Weak Bases from Electromotive-Force Measurements of Solutions of Partially Hydrolyzed Salts
}

\author{
By Roger G. Bates and Gladys D. Pinching
}

\begin{abstract}
A method for the determination of dissociation constants of weak electrolytes by electromotive-force measurements of solutions of partially hydrolyzed salts of a weak acid and a weak base is described. Although the precision is only half that of the conventional emf method, this procedure has particular advantage in determining the dissociation constants of certain bases, for some of the experimental difficulties encountered in adapting the usual method to solutions containing these bases can be overcome or reduced. The hydrogen-ion concentration of a solution of a salt of this type depends upon the constants of the weak acid, the weak base, and water. If two of these are known, the third can be evaluated by means of emf measurements without the necessity of knowing the exact hydrogen-ion concentration, which is usually difficult to obtain. Hydrogen electrodes and silver-silver chloride electrodes are used in the cells, and the solutions are aqueous mixtures containing the ions of the salt and an alkali chloride. The equations for the calculation of dissociation constants are developed. The method was tested by a determination of the basic dissociation constant of tris(hydroxymethyl)aminomethane at $20^{\circ}, 25^{\circ}$, and $30^{\circ} \mathrm{C}$ from three series of measurements: (a) by the conventional emf method; (b) by emf studies of the hydrolysis of mixtures of the amine and primary potassium phosphate; and (c) by emf studies of the hydrolysis of mixtures of the amine and potassium $p$-phenolsulfonate. The three determinations were in acceptable agreement. The negative logarithm of the basic dissociation constant, $\mathrm{p} K_{b}$, was found to be 5.946 at $20^{\circ}, 5.920$ at $25^{\circ}$, and 5.896 at $30^{\circ} \mathrm{C}$.
\end{abstract}

\section{Introduction}

Although the experimental difficulties met in the study of most weak bases are not insurmountable, they have been in large part responsible for the failure of this important class of substances to receive the attention it deserves. The hydrogensilver chloride cell, so useful in precise determinations of the dissociation constants of weak acids by the electromotive-force method $[1,2,3]^{1}$ can be successfully applied to a measurement of the constant of ammonia only under special conditions [4]. Thus, if equimolal mixtures of ammonia and ammonium chloride are to be investigated by this method, one must not only determine and apply corrections for the volatility of ammonia

\footnotetext{
${ }^{1}$ Figures in brackets indicate the literature references at the end of this
} paper.

Dissociation Constants of Bases and for the solubility of silver chloride but must retard the diffusion of silver to the hydrogen electrode as well.

Replacement of the silver-silver chloride electrode by a type less susceptible to reaction with ammonia bases has been suggested $[5,6]$, but some sacrifice of reproducibility may be expected [7]. Furthermore, it is desirable in the interest of consistency that dissociation constants of bases should relate to the same cell used extensively in studies of weak acids and in measuring the ionization constant of water. Nevertheless, the extrapolation to infinite dilution to obtain the thermodynamic constant of a monoacidic base entails a greater uncertainty than for a monobasic acid, where the activity-coefficient term is practically zero, or at worst a linear function of ionic strength. 
It is well known that the $\mathrm{pH}$ of an aqueous solution of a salt of "two-sided weakness", that is, a salt formed by neutralization of a weak acid with a weak base, is fixed by the concentration and by the dissociation constants of the acid, the base, and water. These three constants are designated by the symbols $K_{a}, K_{b}$, and $K_{w}$, respectively. Unfortunately, the $\mathrm{pH}$ cannot be uniquely determined [8]. However, these dissociation constants can be expressed in terms of the measured electromotive force of galvanic cells composed of hydrogen and silver-silver chloride electrodes immersed in solutions of the weak salt with added chloride. The value of $K_{a} K_{w} / K_{b}$ can be obtained by a suitable extrapolation to zero concentration of salt ions. A knowledge of the hydrogen-ion concentration or activity is then unnecessary.

The extent of hydrolysis of the salt depends upon the relative magnitudes of $K_{a}$ and $K_{w} / K_{3}$. For best results, the acid and base should be of such strengths that at least 5 percent of each of the two salt ions is hydrolyzed, thus assuring an adequate buffer capacity. Similarly, degrees of hydrolysis greater than 95 percent should be avoided. In general, this restriction means that $\log K_{a}$ and $\log \left(K_{w} / K_{b}\right)$ should differ by no more than 2 .

This emf-hydrolysis method is often better suited to the determination of the dissociation constants of weak bases than is the conventional emf method. The low buffer capacity near the ends of the pH-neutralization curve and the difficulty of evaluating the buffer ratio precisely in these regions usually restrict the application of the conventional method to solutions with buffer ratios between 0.2 and 5 . Nevertheless, a low ratio of free base to salt is sometimes desired in order to minimize losses by volatilization and errors caused by the high solubility of silver chloride in the cell solutions. If $K_{a}$ for the acid selected is larger than $K_{w} / K_{b}$, less than half of the base ion will usually be transformed into free base, and these errors may be of little or no consequence. Under these conditions the buffer ratio may depart widely from unity, but this disadvantage is offset by the double buffering action offered by the two systems set up by the incomplete reaction of the salt ions with water. Furthermore, the buffer ratio need not be established with great accuracy. If the free base is uncharged and the acid chosen is a singly charged anion, the activity-coefficient term is usually small and the extrapolation to zero salt concentration is easily effected.

The solutions needed to determine the dissociation constant of a weak base by the emf-hydrolysis method are usually not difficult to prepare. If the free base is a solid and is readily obtained in the pure state, it is weighed and combined in solution with an equivalent amount of the weak acid and the desired amount of alkali chloride. If the acid is not a solid, and if the weak base is most conveniently added in the form of its hydrochloride, the solutions are made from equivalent amounts of base hydrochloride and an alkali salt of the weak acid.

The chief disadvantage of this method results from the dependence of the emf of the cell upon the geometric mean of two constants, that is upon $\sqrt{K_{a}\left(K_{w} / K_{b}\right)}$, instead of upon $K_{o} / K_{b}$ alone, as in the usual emf method. Consequently the precision of determining $K_{b}$ with the aid of known values of $K_{w}$ and $K_{a}$ is reduced by one-half.

Tris(hydroxymethyl)aminomethane was chosen for a comparison of the new procedure with the earlier method. This primary amine can be obtained as a pure solid readily soluble in water and not appreciably volatile. It does not react with silver ion so extensively as to prohibit the use of the silver-silver chloride in equimolal mixtures of the amine and its hydrochloride. Electromotive-force measurements were made at $20^{\circ}, 25^{\circ}$, and $30^{\circ} \mathrm{C}$ on solutions of partially hydrolyzed salts of this amine with primary phosphate ion $\left(\mathrm{H}_{2} \mathrm{PO}_{4}^{-}\right)$and with $p$-phenolsulfonate ion $\left(\mathrm{HOC}_{6} \mathrm{H}_{4} \mathrm{SO}_{3}{ }^{-}\right)$, and the dissociation constant of the base was calculated from the results. The constant was also found by the customary emf method [1, 3]. The three determinations were in acceptable agreement.

\section{Description of the Method}

If the standard potential, $E^{\circ}$, is known, each emf measurement of the hydrogen-silver chloride cell yields a value of $-\log \left(f_{\mathrm{H}} f_{\mathrm{C} 1} m_{\mathrm{H}}\right)$, where $m$ is molality, $f$ is the activity coefficient on the molal scale, and $\mathrm{H}$ designates the total hydrogen-ion species, hydrated or otherwise. This quantity has been called $\mathrm{pwH}$ for convenience and to suggest its status as a practical unit of acidity susceptible of exact definition [8]. The $\mathrm{pwH}$ is calculated from the emf $E$ by

$$
\mathrm{pwH} \equiv-\log \left(f_{\mathrm{H}} f_{\mathrm{Cl}} m_{\mathrm{H}}\right)=\frac{\left(E-E^{\circ}\right) \boldsymbol{F}}{2.3026 R T}+\log m_{\mathrm{Cl}},
$$


where $\boldsymbol{F}, R$, and $T$ are respectively the faraday, gas constant, and temperature on the Kelvin scale. The values of $E^{\circ}$ and $2.3026 R T / \boldsymbol{F}$ are summarized in another publication [4]. Thermodynamic dissociation constants are derived from experimental values of $\mathrm{pwH}$ by expression of $m_{\mathrm{H}}$ or $f_{\mathrm{H}} m_{\mathrm{H}}$ in terms of the constants that fix their values in the cell solutions, and extrapolation of a suitable function of the dissociation constants to zero concentration where the activity coefficients become unity.

Three equilibria are of significance in determining the hydrogen-ion concentration in a solution of a salt of a weak acid anion, $\mathrm{HA}^{-}$, and weak monoacidic base, B. ${ }^{2}$ These are the acidic dissosociation of the weak acid,

$$
\mathrm{HA}^{-}+\mathrm{H}_{2} \mathrm{O}=\mathrm{H}_{3} \mathrm{O}^{+}+\mathrm{A}^{=} ; K_{a}
$$

the basic dissociation of the weak base,

$$
\mathrm{B}+\mathrm{H}_{2} \mathrm{O}=\mathrm{BH}^{+}+\mathrm{OH}^{-} ; K_{b}
$$

and the ionization of water,

$$
2 \mathrm{H}_{2} \mathrm{O}=\mathrm{H}_{3} \mathrm{O}^{+}+\mathrm{OH}^{-} ; K_{w}
$$

The equilibria among water and the salt ions $\mathrm{BH}^{+}$and $\mathrm{A}^{=}$are expressed in terms of the three above:

$$
\mathrm{BH}^{+}+\mathrm{H}_{2} \mathrm{O}=\mathrm{B}+\mathrm{H}_{3} \mathrm{O}^{+} ; K_{b h}=K_{w} / K_{b},
$$

and

$$
\mathrm{A}^{=}+\mathrm{H}_{2} \mathrm{O}=\mathrm{HA}^{-}+\mathrm{OH}^{-} ; K_{w} / K_{a} .
$$

In terms of the Brønsted-Lowry theory of acids and bases $[9,10]$, eq 3 a represents the acidic dissociation of $\mathrm{BH}^{+}$, the conjugate acid of the base $\mathrm{B}$, and eq $3 \mathrm{~b}$ represents the dissociation of the (hydrated) anion $\mathrm{A}^{=}$as a base. Evidently the extent to which the separate reactions $3 \mathrm{a}$ and $3 \mathrm{~b}$ proceed to establish equilibrium is largely dependent upon the acidic and basic strengths of $\mathrm{BH}^{+}$ and $\mathrm{A}^{=}$in comparison with the amphiprotic solvent. If $\mathrm{B}$ is a rather strong base (and its conjugate acid $\mathrm{BH}^{+}$correspondingly weak), the hydrolysis of $\mathrm{BH}^{+}$by eq $3 \mathrm{a}$ will proceed but slightly unless one of the products, hydrogen ion or free base, is removed. Similarly, if $\mathrm{HA}^{-}$is a stronger acid than is water, $\mathrm{A}^{=}$will be a weak

\footnotetext{
2 The equations can be derived in a similar manner for acids and bases of
} other electric types. base, and eq $3 \mathrm{~b}$ will also show little tendency to take place. However, when both $\mathrm{BH}^{+}$and $\mathrm{A}^{=}$ are part of the same aqueous system, the several acids and bases present interact, and hydrolysis is no longer dependent solely upon the acidic and basic properties of water. For example, $\mathrm{BH}^{+}$ will be hydrolyzed to a larger extent in the presence of $\mathrm{A}^{=}$than by water alone, if $\mathrm{A}^{=}$is a stronger base than water. The acid strength of $\mathrm{BH}^{+}$has a similar influence upon the extent to which eq $3 \mathrm{~b}$ proceeds. This behavior is quite adequately explained by eq $3 \mathrm{a}$ and $3 \mathrm{~b}$, for the concentrations of hydronium and hydroxyl ions cannot be varied independently in the same solution.

By combination of eq $3 \mathrm{a}$ with $3 \mathrm{~b}$, one can write the complete equation for the simultaneous hydrolysis of the ions $\mathrm{BH}^{+}$and $\mathrm{A}^{=}$:

$$
\begin{gathered}
\mathrm{BH}^{+}+\mathrm{A}^{=}+2 \mathrm{H}_{2} \mathrm{O}= \\
\mathrm{B}+\mathrm{HA}^{-}+\mathrm{H}_{3} \mathrm{O}^{+}+\mathrm{OH}^{-} ; K_{w}^{2} / K_{a} K_{b} .
\end{gathered}
$$

It is clear that the two ions will not usually hydrolyze to equal extents, for $K_{a}$ and $K_{b}$ (and consequently the constants of eq $3 \mathrm{a}$ and $3 \mathrm{~b}$ ) will ordinarily be different. Hence, it is incorrect to apply the term "degree of hydrolysis" to a salt of a weak acid and a weak base. It should rather be applied to each of the salt ions individually. If $K_{a}$ and $K_{b}$ were indeed equal, and thus the degrees of hydrolysis of the individual ions as well, hydronium and hydroxyl ions would be produced in equal numbers upon dissolving the salt in water, as equilibrium 4 indicates; and the solution would remain neutral, or substantially so, at all concentrations. The inequality of $K_{a}$ and $K_{b}$ not only causes the solution to be acidic or alkaline but also gives rise to a change of $\mathrm{pH}$ with concentration [11].

In order to calculate $m_{\mathrm{H}}$ or $f_{\mathrm{H}} m_{\mathrm{H}}$ in a solution of this type, the fraction of $\mathrm{BH}^{+}$hydrolyzed will be designated $\alpha_{1}$, and the corresponding degree of hydrolysis of the acid anion $\mathrm{A}^{=}$will be called $\alpha_{2}$. Hence, from the mass-law expression for equilibrium $3 \mathrm{a}$ one can write

$$
-\log K_{b h}=-\log f_{\mathrm{H}} m_{\mathrm{H}}+\log \frac{1-\alpha_{1}}{\alpha_{1}}+\log \frac{f_{\mathrm{NH}_{4}}{ }^{+}}{f_{\mathrm{NH}_{3}}},
$$

and from eq $2 \mathrm{a}$

$$
-\log K_{a}=-\log f_{\mathrm{H}} m_{\mathrm{H}}+\log \frac{\alpha_{2}}{1-\alpha_{2}}+\log \frac{f_{\mathrm{HA}^{-}}}{f_{\mathrm{A}^{-}}} .
$$


These equations, together with that for the water equilibrium, regulate the hydrogen-ion concentration. By combination of eq 1, 5a, and $5 \mathrm{~b}$ we obtain

$$
\begin{array}{r}
\frac{\mathrm{p} K_{b h}+\mathrm{p} K_{a}}{2}=-\log \sqrt{K_{b h} K_{a}}=\mathrm{pwH}+ \\
1 / 2 \log \frac{\alpha_{2}\left(1-\alpha_{1}\right)}{\alpha_{1}\left(1-\alpha_{2}\right)}+1 / 2 \log \frac{f_{\mathrm{BH}^{+} f_{\mathrm{HA}}-f_{\mathrm{Cl}^{-}}^{2}}}{f_{\mathrm{B}} f_{\mathrm{A}}=}
\end{array}
$$

As usual, $\mathrm{p} K \equiv-\log K$. The analogy with the equations for the product of the constants for overlapping successive dissociation steps of polybasic acids [12] is evident.

\section{Calculation of the $\alpha$ Term}

From a consideration of eq $3 \mathrm{a}$ and $3 \mathrm{~b}$, the relationship between $\alpha_{1}$ and $\alpha_{2}$ can be derived. Hydronium ion and hydroxyl ion are produced by these reactions in the molal amounts $\alpha_{1} m$ and $\alpha_{2} m$, respectively, where $m$ is again the stoichiometric molality of each of the ions of the salt, usually not less than 0.01. By reaction with the other ion, either hydronium or hydroxyl is reduced to a negligible concentration. If the salt solution is neutral, $\alpha_{1} \approx \alpha_{2}$. If acidic,

$$
\alpha_{1}-\alpha_{2} \approx m / m_{\mathrm{H}} \text {. }
$$

If alkaline,

$$
\alpha_{2}-\alpha_{1} \approx m / m_{\mathrm{OH}} \text {. }
$$

In the determination of basic dissociation constants, an acid of known dissociation is selected. Equation $5 \mathrm{~b}$ can be converted to a form convenient for calculating $\alpha_{2}$ :

$$
\log \frac{1-\alpha_{2}}{\alpha_{2}} \approx \mathrm{pwH}-\mathrm{p} K_{a}+\frac{2 A \sqrt{\mu}}{1+B a^{*} \sqrt{\mu}},
$$

where $A$ and $B$ are constants of the DebyeHückel theory [13], $\mu$ is the ionic strength, and $a^{*}$ is an adjustable parameter whose value usually lies between 0 and 10 . An average value, for example 4, suffices for the purpose. It is desirable that $\alpha_{2}$ should not be much less than 0.1. Hence pwH should not be more than about 1 unit greater than $\mathrm{p} K_{a}$.

An approximate $\alpha_{2}$ with which to evaluate the ionic strength is obtained from eq 7 . For the first approximation, the ionic strength of mixtures of base, acid, and potassium chloride, each at mo- lality $m$, is taken as $4 m$. Then a more accurate value is obtained by

$\mu=4 m-m\left(3 \alpha_{2}+\alpha_{1}\right) / 2+\left(m_{\mathrm{H}}+m_{\mathrm{OH}}\right) / 2 \approx 4 m\left(1-\alpha_{2} / 2\right)$.

The simpler expression for $\mu$ given in the last part of eq 9 is adequate when pwH is between 4 and 10 . With $\alpha_{2}$ from eq 8 and $m_{\mathrm{H}}$ or $m_{\mathrm{OH}}$ (depending upon whether the solution is acidic or alkaline) calculated from $\mathrm{pwH}$ by

and

$$
-\log m_{\mathrm{H}}=\mathrm{pwH}-\frac{2 A \sqrt{\mu}}{1+B a^{*} \sqrt{\mu}}
$$

$$
-\log m_{\mathrm{OH}} \approx \mathrm{p} K_{w}-\mathrm{pwH},
$$

$\alpha_{1}$ can be obtained by eq $7 \mathrm{a}$ or $7 \mathrm{~b}$, and the second term on the right of eq 6 can be evaluated. This term is quite small if $\alpha_{2}$ exceeds 0.1 and the $\mathrm{pH}$ lies between 4 and 10. It is less than 0.0001 for equimolal mixtures of tris(hydroxymethyl)aminomethane and primary potassium phosphate at $20^{\circ}$ to $30^{\circ} \mathrm{C}$ when $m$ is 0.01 or greater. For a corresponding mixture of the amine and potassium $p$-phenolsulfonate, it amounts to 0.0004 at $m=$ 0.01 .

\section{The Extrapolation}

If the Debye-Hückel relation between ionic charge and activity coefficient were valid for these mixtures, the last term of eq 6 would be zero. The data presented in a later section indicate that this is not the case for equal molal mixtures of tris (hydroxymethyl)aminomethane, potassium dihydrogen phosphate (or potassium p-phenolsulfonate), and potassium chloride.

The last term of eq 6 can be divided into two parts. The first, $f_{\mathrm{BH}^{+}} f_{\mathrm{Cl}^{-}}-f_{\mathrm{B}}$, pertains to the base, and the second, $f_{\mathrm{HA}^{-}}-f_{\mathrm{Cl}^{-}}-/ f_{\mathrm{A}}=$, to the weak acid. It has been found that an activity-coefficient term of the first type (where $\mathrm{B}$ is $\mathrm{NH}_{3}$ ) can be represented satisfactorily by

$$
1 / 2 \log \frac{f_{\mathrm{BH}^{+} f_{\mathrm{Cl}^{-}}^{-}}}{f_{\mathrm{B}}}=-\frac{A \sqrt{\mu}}{1+B a_{1} \sqrt{\mu}}+\beta_{1} \mu,
$$

where $\beta_{1}$ is a second parameter [4]. Likewise, the term for the acid system can be expressed similarly, as studies of the phosphate and phenolsulfonate buffers $[14,15]$ have shown.

$$
1 / 2 \log \frac{f_{\mathrm{HA}^{-}} f_{\mathrm{Cl}^{-}}}{f_{A^{-}}}=\frac{A \sqrt{\mu}}{1+B a_{2} \sqrt{\mu}}+\beta_{2} \mu .
$$


If $a_{1}$ and $a_{2}$ were equal, the last term of eq 6 would be a linear function of ionic strength. That it was not found to be so suggests that $a_{1}$ differs from $a_{2}{ }^{3}$

It is desired simply to find an empirical expression that will reduce the last term of eq 6 to a linear function of ionic strength and hence facilitate the extrapolation to zero concentration. From eq 12 and 13 ,

$$
\begin{gathered}
\frac{A B\left(a_{1}-a_{2}\right) \mu}{\left(1+B a_{1} \sqrt{\mu}\right)\left(1+B a_{2} \sqrt{\mu}\right)}=1 / 2 \log \frac{f_{\mathrm{BH}^{+}} f_{\mathrm{HA}^{-}} f_{\mathrm{Cl}}^{2}}{f_{B} f_{A}=}+\beta_{\mu}^{\prime} \\
\approx \frac{A B\left(a_{1}-a_{2}\right) \mu}{(1+B \bar{a} \sqrt{\mu})^{2}},
\end{gathered}
$$

where $\bar{a}$ is $\left(a_{1}+a_{2}\right) / 2$, and $\beta^{\prime}$ is the slope of a plot of the left (or extreme right) side of eq 14 as a function of $\mu$. The approximate form (extreme right of eq 14) was found to yield a satisfactory straight line and was somewhat easier to compute than the exact left-hand term. The value of $\beta^{\prime}$ differs, of course, with the form of equation chosen.

"Apparent" values of the mean of $\mathrm{p} K_{b h}$ and $\mathrm{p} K_{a}$, namely $\left[\left(\mathrm{p} K_{b h}+\mathrm{p} K_{a}\right) / 2\right]^{\prime}$, are therefore computed by eq 6 for various values of $a_{1}$ and $a_{2}$ with ionic strengths established as described in the foregoing section. These values are plotted as a function of $\mu$, and the shape of the curve is examined. If necessary, $\bar{a}$ is varied until a straight line results. It is evident that $a_{1}-a_{2}$ in the numerator of eq 14 can be adjusted to alter the slope of the extrapolation plot if desired without affecting its curvature, so long as $\bar{a}$ remains unchanged. At zero ionic strength the activitycoefficient term is zero, and the intercept is the true mean of the thermodynamic constants, $1 / 2$ $\left(\mathrm{p} K_{b h}+\mathrm{p} K_{a}\right)$. Inasmuch as $\mathrm{p} K_{b h}=\mathrm{p} K_{w}-\mathrm{p} K_{b}$, and both $K_{a}$ and $K_{w}$ are known, the basic constant is readily obtained.

\section{Experimental Procedures}

Purified tris(hydroxymethyl)aminomethane was obtained through the courtesy of Commercial Solvents Corporation. The commercial grade of amine had been decolorized and crystallized three times from a mixture of methanol and water. ${ }^{4}$

\footnotetext{
${ }^{3}$ Actually $a_{1}$ for the ammonia system was found to be about 2 [4], and values of 4.4 and 8 for $a_{2}$ were found for phosphate and phenolsulfonate buffer solutions [14, 15]. However, it would be surprising if the parameters remained unchanged in these solutions of partially hydrolyzed salts.

4 Communication from $J_{0}$ hn A. Riddick.
}

Two samples, titrated with a standard solution of hydrochloric acid, required amounts of acid equivalent to 100.02 percent of the base. A mixture of bromcresol green and alizarin red $S$ was used as indicator for one sample (see footnote 4) and the sodium salt of methyl red for the other. Color standards, adjusted to $\mathrm{pH} 4.8$, the theoretical end-point in $0.05-M$ solution computed from the dissociation constant found by Glasstone and Schram [16], were used. The solubility of freshly precipitated silver chloride in two solutions of the amine was determined at room temperature. A $0.1-M$ solution of the amine dissolved 0.0021 mole of silver chloride per liter, and a $0.1-M$ solution that was also $0.01 M$ with respect to potassium chloride dissolved 0.0007 mole. Hence, the solubility of silver chloride is considerably less than in solutions of ammonia, and it is safe to conclude that no correction is necessary for the solubility in equimolal solutions of the amine and its hydrochloride.

The potassium dihydrogen phosphate was NBS Standard Sample 186 I. Potassium $p$ phenolsulfonate was decolorized and then crystallized four times. The last crystallization was from freshly boiled conductivity water. The salt was dried at $90^{\circ}$ to $110^{\circ} \mathrm{C}$. The $\mathrm{pH}$ of the $0.1-M$ solutions was found by glass-electrode measurement to be about 5.1. This is close to the inflection point. The potassium chloride had been purified by treatment with chlorine, precipitation with gaseous hydrogen chloride, and fusion [17]. Hydrochloric acid was distilled and the middle fraction collected and diluted to about $0.1 \mathrm{M}$. Five separate determinations of the concentration of this standard solution by weighing silver chloride gave a mean deviation from the mean of less than 0.02 percent.

For the mixtures of amine and weak acid, the cell vessels were of the type ordinarily used for studies of weak-acid systems [18], that is, with a single saturator and no stopcock between the electrode compartments. Those employed previously in the investigation of ammonia solutions [4] were used for mixtures of amine and hydrochloric acid. In view of the low volatility of the amine, however, the presaturator was not required. Air was removed from the solutions by passage of nitrogen before the final weighing. 


\section{Results}

The electromotive force of cells with hydrogen electrodes and silver-silver chloride electrodes and containing equimolal mixtures of tris(hydroxymethyl)aminomethane, potassium dihydrogen phosphate (or potassium $p$-phenolsulfonate), and potassium chloride is listed in table 1 . The emf has been corrected in the usual manner to a partial pressure of $1 \mathrm{~atm}$ of hydrogen. Table 2 gives the electromotive force of the same cell containing 15 aqueous mixtures of tris(hydroxymethyl)aminomethane and its hydrochloride. These data were obtained in order that the constant of the amine might be evaluated by the earlier or "conventional" method to furnish a test of the newer method based upon emf studies of partially hydrolyzed salts.

TABLE 1. Electromotive force of hydrogen-silver chloride cells containing solutions of tris(hydroxymethyl)aminomethane, weak acid, and potassium chloride, each at molality $m$

\begin{tabular}{|c|c|c|c|}
\hline \multirow{2}{*}{$m$} & \multicolumn{3}{|c|}{ Electromotive force at - } \\
\hline & $20^{\circ}$ & $25^{\circ}$ & $30^{\circ}$ \\
\hline \multicolumn{4}{|c|}{ AMINE+POTASSIUM DIHYDROGEN PHOSPHATE } \\
\hline $\begin{array}{l}0.08038 \\
.05526 \\
.03555 \\
.02025 \\
.011629\end{array}$ & $\begin{array}{r}0.73985 \\
.74892 \\
.75980 \\
.77369 \\
.78737\end{array}$ & $\begin{array}{r}0.74098 \\
.75019 \\
.76106 \\
.77524 \\
.78915\end{array}$ & $\begin{array}{r}0.74189 \\
.75124 \\
.76230 \\
.77678 \\
.79085\end{array}$ \\
\hline \multicolumn{4}{|c|}{ AMINE+POTASSIUM $p$-PHENOLSULFONATE } \\
\hline $\begin{array}{l}0.08111 \\
.05667 \\
.03622 \\
.019945 \\
.010458\end{array}$ & $\begin{array}{r}0.79604 \\
.80452 \\
.81525 \\
.82968 \\
.84545\end{array}$ & $\begin{array}{r}0.79687 \\
.80546 \\
.81634 \\
.83104 \\
.84705\end{array}$ & $\begin{array}{r}0.79761 \\
.80637 \\
.81741 \\
.83240 \\
.84863\end{array}$ \\
\hline
\end{tabular}

Table 3 lists the mean of $\mathrm{p} K_{b h}$ and $\mathrm{p} K_{a}$ calculated from the data in table 1 by the method described in earlier sections. The values of $\mathrm{p} K_{b n}$ obtained from these two series of measurements are listed in the last column. The values of $\mathrm{p} K_{a}$ were taken as $7.213,7.198$, and 7.189 for primary phosphate ion at $20^{\circ}, 25^{\circ}$, and $30^{\circ} \mathrm{C}$, respectively $[14,18]$; and $9.105,9.053$, and 9.005 for $p$-phenolsulfonate ion at the same temperatures [15]. The mean value of $\mathrm{p} K_{b h}$ obtained by the earlier method of Roberts [1] and Harned and Ehlers [3] from the
TABLE 2. Electromotive force of hydrogen-silver chloride cells containing solutions of tris(hydroxymethyl)aminomethane $\left(m_{1}\right)$ and its hydrochloride $\left(m_{2}\right)$

\begin{tabular}{|c|c|c|c|}
\hline \multirow{2}{*}{$m_{2}$} & \multicolumn{3}{|c|}{ Electromotive force at- } \\
\hline & $20^{\circ}$ & $25^{\circ}$ & $30^{\circ}$ \\
\hline \multicolumn{4}{|c|}{$m_{1}=m_{2}$} \\
\hline $\begin{array}{r}0.08814 \\
.07097 \\
.05099 \\
.02996 \\
.02564 \\
.015268 \\
.009962 \\
.009785 \\
.006092 \\
.003924\end{array}$ & $\begin{array}{r}0.77789 \\
.78240 \\
.78940 \\
.80092 \\
.80436 \\
.81585 \\
.82541 \\
.82593 \\
.83669 \\
.84667\end{array}$ & $\begin{array}{r}0.77594 \\
.78050 \\
.78757 \\
.79923 \\
.80266 \\
.81432 \\
.82414 \\
.82455 \\
.83560 \\
.84574\end{array}$ & $\begin{array}{r}0.77376 \\
.77838 \\
.78557 \\
.79741 \\
.80099 \\
.81283 \\
.82273 \\
.82329 \\
.83445 \\
.84477\end{array}$ \\
\hline \multicolumn{4}{|c|}{$m_{1}=0.3630 m_{2}$} \\
\hline $\begin{array}{r}0.09959 \\
.07933 \\
.05982 \\
.03974 \\
.02024\end{array}$ & $\begin{array}{r}0.74998 \\
.75472 \\
.76066 \\
.76931 \\
.78415\end{array}$ & $\begin{array}{r}0.74738 \\
.75220 \\
.75819 \\
.76694 \\
.78201\end{array}$ & $\begin{array}{r}0.74474 \\
.74960 \\
.75569 \\
.76458 \\
.77985\end{array}$ \\
\hline
\end{tabular}

data given in table 2 is also listed in the last column. The following equation was used:

$$
\begin{aligned}
& -\log K^{\prime} \equiv-\log K_{b h}-\beta m_{2}=\mathrm{pwH}+ \\
& \quad \log \frac{m_{2}}{m_{1}}-\frac{2 A \sqrt{m_{2}}}{1+B a^{*} \sqrt{m_{2}}} .
\end{aligned}
$$

TABLE 3. Values of $1 / 2\left(\mathrm{p} K_{b h}+\mathrm{p} K_{a}\right)$ and $\mathrm{p} K_{b h}$ derived

\begin{tabular}{|c|c|c|}
\hline Acid & $\frac{\mathrm{p} K_{b h}+\mathrm{p} K_{a}}{2}$ & $\mathrm{p} K_{b h}$ \\
\hline \multicolumn{3}{|c|}{$20^{\circ}$} \\
\hline $\begin{array}{l}\mathrm{KH}_{2} \mathrm{PO}_{4} \\
\mathrm{KH} \text { Phenolsulfonate } \\
\mathrm{HCl}\end{array}$ & $\begin{array}{l}7.7175 \pm 0.0006 \\
8.6630 \pm .0002\end{array}$ & $\begin{array}{l}\text { 8. } 2220 \pm 0.0012 \\
\text { 8. } 2210 \pm .0004 \\
\text { 8. } 2214 \pm .0009\end{array}$ \\
\hline \multicolumn{3}{|c|}{$25^{\circ}$} \\
\hline $\begin{array}{l}\mathrm{KH}_{2} \mathrm{PO}_{4} \\
\mathrm{KH} \text { Phenolsulfonate } \\
\mathrm{HCl}\end{array}$ & $\begin{array}{l}7.6370 \pm 0.0004 \\
8.5642 \pm .0004\end{array}$ & $\begin{array}{l}8.0760 \pm 0.0009 \\
8.0755 \pm .0007 \\
8.0766 \pm .0007\end{array}$ \\
\hline \multicolumn{3}{|c|}{$30^{\circ}$} \\
\hline $\begin{array}{l}\mathrm{KH}_{2} \mathrm{PO}_{4} \\
\mathrm{KH} \text { Phenolsulfonate } \\
\mathrm{HCl}\end{array}$ & $\begin{array}{l}7.5622 \pm 0.0008 \\
8.4710 \pm .0004\end{array}$ & $\begin{array}{l}\text { 7. } 9355 \pm 0.0017 \\
\text { 7. } 9371 \pm .0009 \\
\text { 7. } 9391 \pm .0010\end{array}$ \\
\hline
\end{tabular}
from three series of emf measurements 


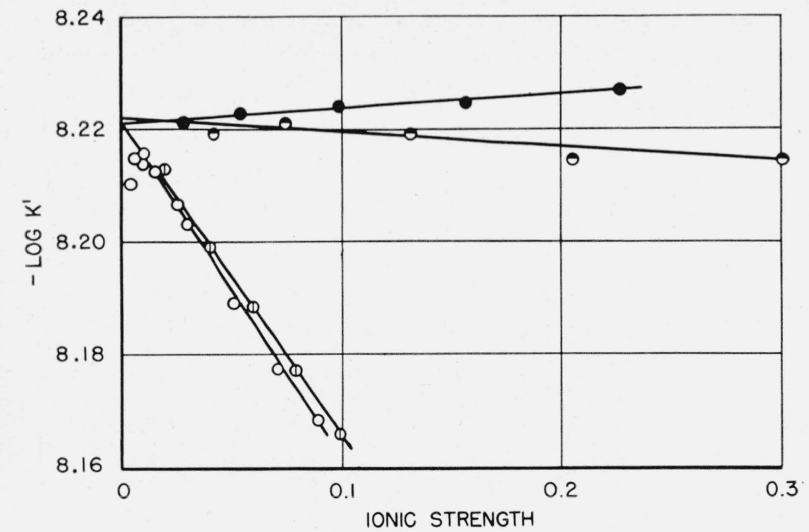

Figure 1. Determination of $K_{b h}$ for tris(hydroxymethyl)aminomethane at $20^{\circ} \mathrm{C}$.

Dots, hydrolysis of amine-phenolsulfonate mixtures; half-shaded circles, hydrolysis of amine-phosphate mixtures; open circles and marked circles, amine- $\mathrm{HCl}$ mixtures.

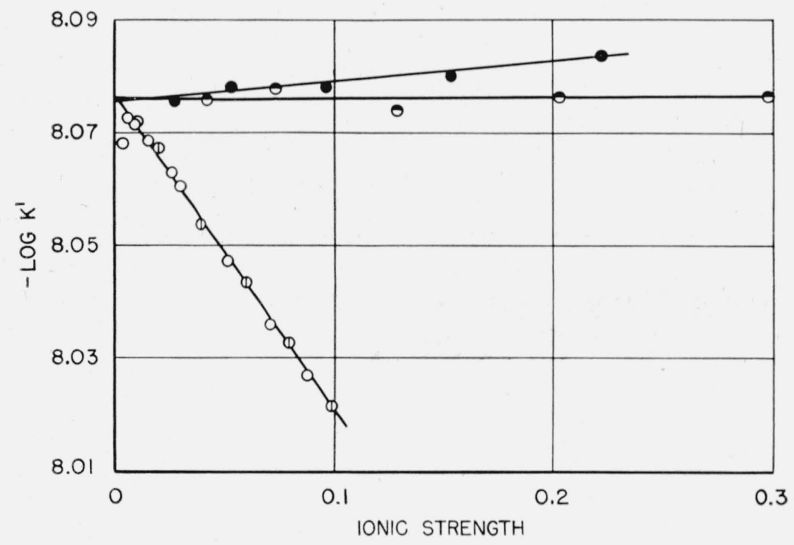

Figure 2. Determination of $K_{b h}$ for tris(hydroxymethyl)aminomethane at $25^{\circ} \mathrm{C}$.

Dots, hydrolysis of amine-phenolsulfonate mixtures; half-shaded circles, hydrolysis of amine-phosphate mixtures; open circles and marked circles, amine- $\mathrm{HCl}$ mixtures.

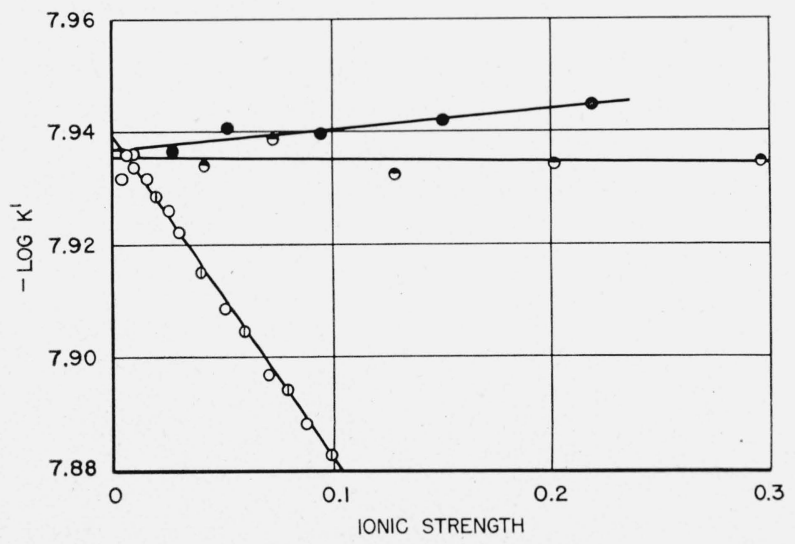

Figure 3. Determination of $K_{b h}$ for tris(hydroxymethyl)aminomethane at $30^{\circ} \mathrm{C}$.

Dots, hydrolysis of amine-phenolsulfonate mixtures; half-shaded circles, hydrolysis of amine-phosphate mixtures; open circles and marked circles, amine- $\mathrm{HCl}$ mixtures.
Figures 1, 2, and 3 illustrate the change with ionic strength of the apparent value of $\mathrm{p} K_{b h}$,

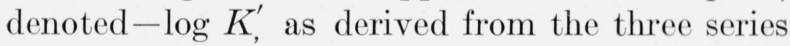
of measurements. The open circles represent points computed from the first ten rows of table 2 and the marked circles from the last five rows. The dots represent amine-phenolsulfonate mixtures and the half-shaded circles mixtures of amine and potassium dihydrogen phosphate. A value of 1 for $a^{*}$ in eq 15 gave the lower lines of each figure. The phosphate points correspond to $a_{1}=3$ and $a_{2}=5$ in the right-hand term of eq 14 , and the phenolsulfonate points were computed with $a_{1}=4$ and $a_{2}=10$. The apparent $K_{b h}$ was obtained by the following formula from the apparent values of the mean given by eq 6 with substitution of the right-hand member of eq 14 for the activity-coefficient term:

$$
-\log K^{\prime}=2\left[\left(\mathrm{p} K_{b h}+\mathrm{p} K_{a}\right) / 2\right]^{\prime}-\mathrm{p} K_{a}
$$

The agreement between the three determinations of $\mathrm{p} K_{b n}$ is satisfactory, in view of the dependence of the results furnished by the emfhydrolysis method upon $K_{a}$ values from other independent investigations. This procedure gives promise of usefulness in other studies of basic dissociation.

A summary of the average values of $\mathrm{p} K_{b h}$ and $K_{b h}$ and of $\mathrm{p} K_{b}$ and $K_{b}$ is given in table 4 . For a calculation of the basic constant, $K_{b}$ (which equals $\left.K_{w} / K_{b h}\right), \mathrm{p} K_{w}$ was taken to be 14.167 at $20^{\circ}$, 13.996 at $25^{\circ}$, and 13.833 at $30^{\circ} \mathrm{C}$ [19]. The value of $-\log K_{b}$ at $25^{\circ} \mathrm{C}(5.920)$ is to be compared with 5.97 found by Glasstone and Schram [16] from measurements with the glass electrode.

TABLE 4. Summary of dissociation constants for tris(hydroxymethyl)aminomethane

\begin{tabular}{|c|c|c|c|c|}
\hline Temperature & $\mathrm{p} K_{b h}$ & $K_{b h} \times 10^{9}$ & $\mathrm{p} K_{b}$ & $K_{b} \times 10^{6}$ \\
\hline${ }^{\circ} \mathrm{C}$ & & & & \\
\hline $20 \ldots$ & 8. 221 & 6. 00 & 5. 946 & 1. 133 \\
\hline $25 \ldots \ldots$ & 8. 076 & 8.40 & 5. 920 & 1. 202 \\
\hline $30 \ldots \ldots$ & 7. 937 & 11.55 & 5. 896 & 1. 272 \\
\hline
\end{tabular}

\section{References}

[1] E. J. Roberts, J. Am. Chem. Soc. 52, 3877 (1930).

[2] H. S. Harned and B. B. Owen, J. Am. Chem. Soc. 52, 5079 (1930).

[3] H. S. Harned and R. W. Ehlers, J. Am. Chem. Soc. 54, 1350 (1932). 
[4] R. G. Bates and G. D. Pinching, J. Research NBS 42, 419 (1949) RP1982.

[5] E. J. Roberts, J. Am. Chem. Soc. 56, 878 (1934).

[6] B. B. Owen, J. Am. Chem. Soc. 56, 2785 (1934).

[7] E. W. Kanning and A. F. Schmelzle, Proc. Indiana Acad. Sci. 51, 150 (1941).

[8] R. G. Bates, Chem. Rev. 42, 1 (1948).

[9] T. M. Lowry, J. Soc. Chem. Ind. 42, 43 (1923).

[10] J. N. Brønsted, Rec. trav. chim. 42, 718 (1923).

[11] R. O. Griffith, Trans. Faraday Soc. 17, 525 (1922).

[12] R. G. Bates, J. Am. Chem. Soc. 7o, 1579 (1948).

[13] G. G. Manov, R. G. Bates, W. J. Hamer, and S. F. Acree, J. Am. Chem. Soc. 65, 1765 (1943).

[14] R. G. Bates and S. F. Acree, J. Research NBS 34, 373 (1945) RP1648.
[15] R. G. Bates, G. L. Siegel, and S. F. Acree, J. Research NBS 31, 205 (1943) RP1559.

[16] S. Glasstone and A. F. Schram, J. Am. Chem. Soc. 69, 1213 (1947).

[17] G. D. Pinching and R. G. Bates, J. Researcb NBS 37, 311 (1946) RP1749.

[18] R. G. Bates and S. F. Acree, J. Research NBS 30, 129 (1943) RP1524.

[19] H. S. Harned and B. B. Owen, The physical chemistry of electrolytic solutions, p. 485. (Reinhold Publishing Corp., New York, N. Y. 1943.)

Washington, July 15, 1949. 